\title{
Dropout From Exercise Programs for Seniors: A Prospective Cohort Study
}

\author{
Maarten Stiggelbout, Marijke Hopman-Rock, Erwin Tak, \\ Lilian Lechner, and Willem van Mechelen
}

\begin{abstract}
This study examines dropout incidence, moment of dropout, and switching behavior in organized exercise programs for seniors in the Netherlands, as determined in a prospective cohort study (with baseline measurements at the start of the exercise program and follow-up after 6 months; $N=1,725$, response rate 73\%). Participants were community-living individuals $50+$ who participated in different forms of organized exercise programs. The average dropout incidence was 0.15 per 6 months, which is lower than that for the general population. The dropout incidence and the timing of dropout differed substantially between the exercise programs. In total, $31 \%$ of people who dropped out of one type of exercise program switched to another type of exercise. The type of program and exercise had a strong effect on differences in this switching behavior. It is recommended that switching behavior be monitored in future studies.
\end{abstract}

Key Words: physical activity, health behavior, health promotion, aging

There is clear evidence of the benefits of exercise programs for older adults (American College of Sports Medicine, 1998). Regular physical activity has been associated with a variety of health benefits such as improved cardiovascular, respiratory, and muscular function and reduction of risk factors associated with chronic disease states. Exercise also plays an important role in enhancing the quality of life of older adults by improving physiological and psychological function, which helps to maintain personal independence and reduces the demand for acute- and chronic-care services (Pate, et al., 1995; U.S. Department of Health and Human Services, 1996). It is therefore important to promote exercise participation among older individuals.

Dropout from exercise programs is a problem (Carmody, Senner, Malinow, \& Matarazzo, 1980; Dishman, 1982; Dishman \& Sallis, 1994; Oldridge, 1988), and

\footnotetext{
Stiggelbout, Hopman-Rock, and Tak are with TNO Quality of Life, Dept. of Physical Activity and Health, 2301 CE Leiden, the Netherlands. Lechner is with the Faculty of Psychology, Open University of the Netherlands, 6401 DL Heerlen, the Netherlands. van Mechelen is with the Dept. of Public and Occupational Health, Institute for Research in Extramural Medicine, VU University Medical Centre, 1081 BT Amsterdam, the Netherlands.
} 
dropout rates in adults of approximately $50 \%$ in the first 6 months, mostly in the first 12 weeks, have been reported (Dishman; Dishman \& Sallis). Unfortunately, it is difficult to compare data because many researchers have neither explicitly defined dropout nor monitored participants over an extended period (Ecclestone, Myers, \& Paterson, 1998; Oldridge, 1982). The available studies generally looked at dropout data for younger adults (i.e., $<50$ years old), and these might not be representative for older populations (King, Blair, Bild, \& Dishman, 1992). Some researchers have suggested that older adults might exercise more consistently because they are more concerned about their health and have more time to exercise than younger adults do (Lee et al., 1996; Oldridge, 1988). In contrast, other researchers have shown that, in community exercise programs, older people are no more compliant than younger people (Ecclestone et al.). Older people might also be more likely to interrupt their exercise programs because the incidence of chronic diseases increases with advancing age.

Obstacles to habitual exercise can lead to lapses, defined as slight periods of nonparticipation in the exercise program, and ultimately to dropout. In our study, we have defined dropout in terms of stopping with a specific exercise program, rather than a cessation of all physical activity. To date, only one study (Ecclestone et al., 1998) investigated the behavior of participants in switching from one exercise program to another. Those authors found that $21 \%$ of the participants switched to another program during the 3 -year study and concluded that older adults join, leave, rejoin, and switch as their commitments and interests change.

The aim of this study was to determine the dropout incidence, moment of dropout in different types of program, and exercise-program-switching behavior of older adults in the Netherlands.

\section{Population and Methods}

This was a prospective cohort study with baseline (at the individual start of the exercise program) and follow-up measurements (6 months after the start).

In collaboration with several experts in the field, 10 different forms of exercise programs were identified as being representative of the exercise programs available to older individuals in the Netherlands, namely, More Exercise for Seniors Gymnastics (MBvO in Dutch), organized sports in sports clubs (specifically, athletics, badminton, cycling, gymnastics, skating, and table tennis), FysioSport (a fitness program delivered by physical therapists/sports physical therapists), Exercise for Heart Patients (HIB in Dutch), and Walking for Sports (referred to as Walking in this article). These exercise programs are supported by national organizations, which facilitated data collection and participant recruitment. Local organizations were approached through the national organizations and recruited clubs or groups that were known to encourage participation by older adults.

Over a period of 15 months, all new members of these clubs or groups were asked to participate in the study. Inclusion criteria were being older than 50 years and not being a member of an organized sports organization directly before the study. The participants gave their written informed consent before joining the study. They completed a baseline questionnaire when they started the exercise program. 
Nonresponders received a reminder after 3 weeks. After 6 months, all participants who had finally returned the first questionnaire received a second questionnaire. Nonresponders to the second questionnaire received a reminder after 3 weeks. The medical-ethics testing committee of TNO approved the study protocol.

Dropout in this study was defined as no longer participating in the specific organized exercise program, according to the respondent. Dropout should be distinguished from lapsing. Lapses were defined as slight periods of nonparticipation in the exercise program, whereas in the case of dropout the cessation is definite. It was specified that one may only call it dropout when one has terminated one's membership in an organization. So, in the case of a seasonal sport such as speed skating, one does not call it dropout when there is a seasonal lapse; speed skaters only drop out if they terminate their membership in the sports club (which was asked for in the questionnaire), which in most cases was not the case.

The baseline questionnaire covered a number of areas. Demographic data were collected concerning age, sex, marital status, level of education, housing situation, and work status. Physical activity was evaluated using questions derived from the Dutch Monitor on Physical Activity and Health (Ooijendijk, Hildebrandt, \& Stiggelbout, 2002), which covers compliance with Dutch public health guidelines during an average week in the summer and winter (Kemper, Ooijendijk, \& Stiggelbout, 2000). These guidelines are based on international guidelines (American College of Sports Medicine, 1998; Pate et al., 1995; U.S. Department of Health and Human Services, 1996). Other lifestyle components such as alcohol consumption (yes/no and how many glasses of alcohol per week) and smoking (nonsmokers, former smokers, and smokers) were also evaluated. Weight and height were recorded and used to calculate body-mass index (BMI; $\left.\mathrm{kg} / \mathrm{m}^{2}\right)$.

Health status was measured with the RAND-36, a multidimensional health questionnaire (Ware \& Sherbourne, 1992) that has been translated into Dutch (van der Zee \& Sanderman, 1993). In this study, five of the nine subscales were used: vitality (reliability: Cronbach's alpha .82), pain (Cronbach's alpha .88), mental health (Cronbach's alpha .85), general feeling of health (Cronbach's alpha .81), and change in health status (a 1-item subscale: no alpha available). Each subscale was scored $0-100$, with 100 being the best score.

In the follow-up questionnaire particular attention was paid to continued participation and dropout, the occurrence of lapses, the frequency of lapses, the duration of lapses (i.e., how long the individual lapses lasted: 1 week, 2-3 weeks, 4-6 weeks, or $>6$ weeks), and the moment of dropout (measured in weeks after the start of the program). To distinguish between lapses and dropout, the participants were asked to fill in questions containing both definitions in the second questionnaire before being asked questions related to dropout and lapsing behavior. In our study we have collected the time point of dropout, but not the time point of lapses. The reason for not taking the time point of lapses was that the occurrence of lapses was predicted as being quite frequent, and we only had two measurements per individual; this would certainly have led to a (too) high amount of memory bias.

Participants who dropped out were asked whether they had taken up another form of exercise, and, if so, which. This was an open-answer question. The answers were then categorized into 17 forms of exercise. 
Statistical analyses were carried out on the data of the participants who completed both questionnaires. Means and standard deviations of the general characteristics were calculated. The adherers and dropouts were compared in univariate analysis for nominal variables using a $\chi^{2}$ test and, for numerical variables, with a $t$ test. The dropout incidence is defined as the number of cases (i.e., people dropping out) in 6 months (available per program) per 100 enrolled participants. The software used was SPSS 11.0 (SPPS Inc., 2003).

\section{Results}

More than 400 local intermediaries (exercise and sport instructors) agreed to recruit participants for the project. After recruitment and giving their informed consent, 2,350 people received the baseline questionnaire and 2,020 completed and returned it. Of these 2,020 participants, 1,725 also returned the follow-up questionnaire at 6 months. The data for these 1,725 participants were analyzed (see Figure 1). The total response rate was $73 \%$.

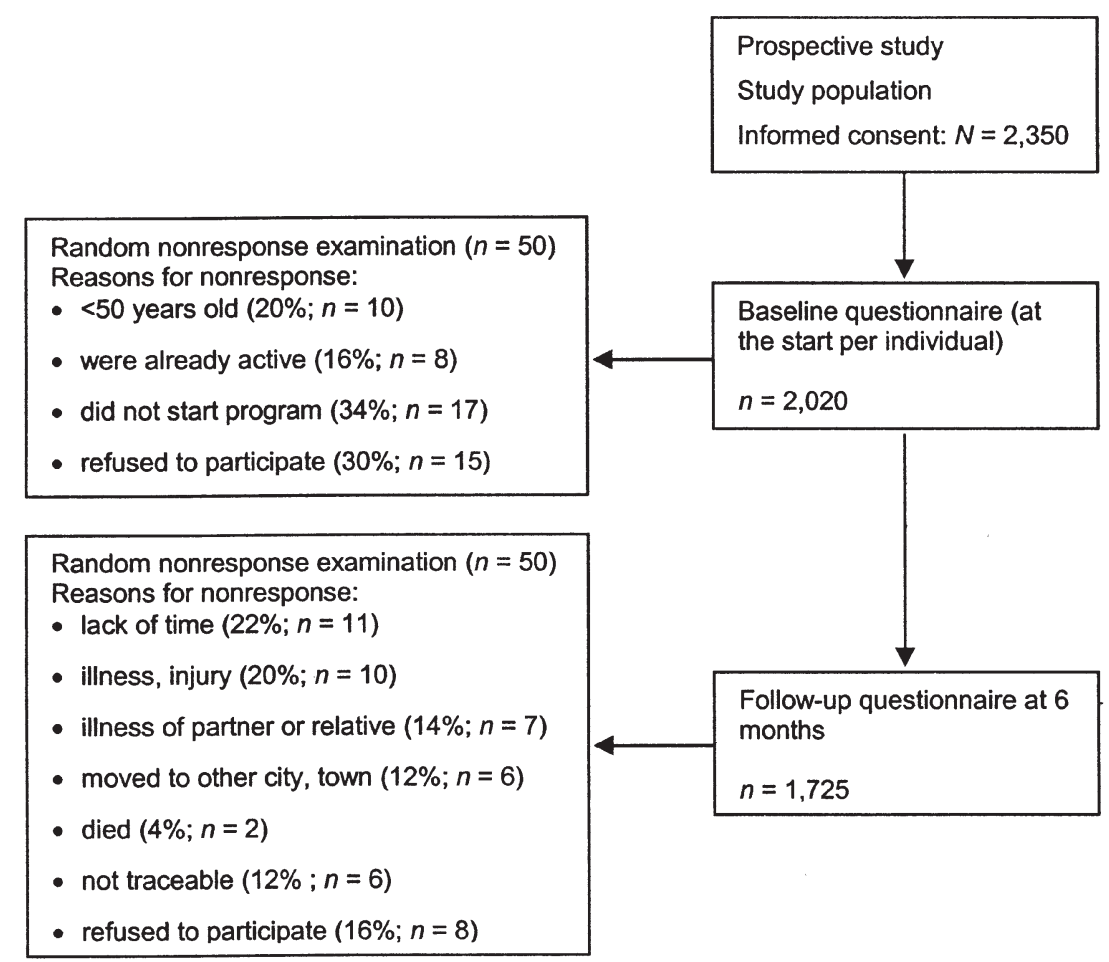

Figure 1 - Flowchart for the study. The information on nonresponse was based on data for a random selection of 50 nonresponders. 
The mean dropout incidence for all programs was 0.15 per 6 months (see Figure 2 ). The highest dropout incidence was for FysioSport (0.37), followed by badminton $(0.25)$ and skating $(0.22)$. The lowest dropout incidence was for cycling (0.05).

\section{Background Characteristics}

Tables $1 \mathrm{~A}$ and $1 \mathrm{~B}$ present the background characteristics of the dropouts $(n=250)$ and the adherers (i.e., the nondropouts; $n=1,475$ ). There were no differences between the dropouts and the adherers in age, sex, housing situation, working status, and lifestyle factors (physical activity, smoking, and alcohol consumption). There were, however, significant differences in marital status, level of education, and BMI. More people who had always been single and fewer widowed people reported dropping out. Fewer people with a low level of education dropped out compared with people with a higher level of education. More underweight people $(\mathrm{BMI}<20)$ and overweight people $(\mathrm{BMI}>25)$ dropped out than did people with normal weight (BMI 20-25). There were also significant differences between the dropouts and the adherers in health status: Dropouts reported lower scores on vitality and a general feeling of health, and they reported lower pain scores (i.e., they experienced more pain).

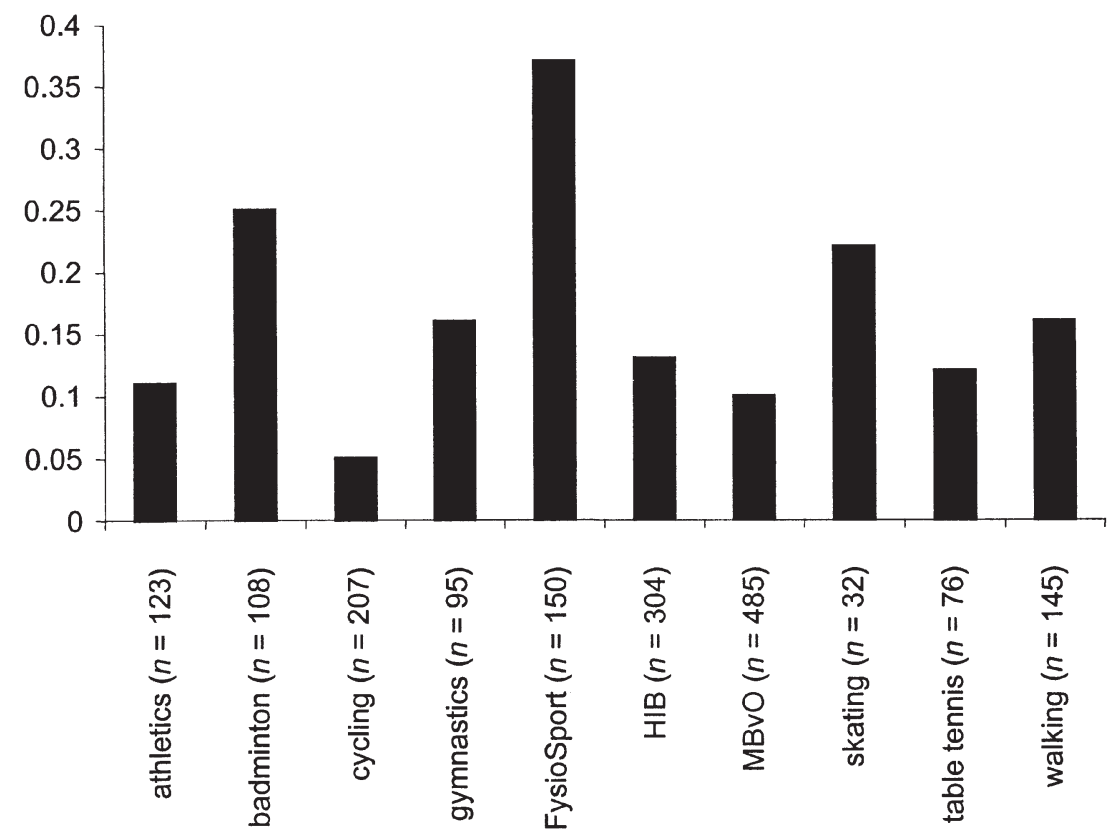

Figure 2 - Six-month dropout incidence for different exercise programs (number between 0 and 1). 
Table 1A Background Characteristics of Participants at Baseline

\begin{tabular}{|c|c|c|c|c|c|c|c|}
\hline \multirow[b]{2}{*}{ Background variable } & \multicolumn{2}{|c|}{$\begin{array}{l}\text { Adherers } \\
(n=1,475)\end{array}$} & \multicolumn{2}{|c|}{$\begin{array}{l}\text { Dropouts } \\
(n=250)\end{array}$} & \multicolumn{2}{|c|}{$\begin{array}{c}\text { Total } \\
(N=1,725)\end{array}$} & \multirow{2}{*}{$\begin{array}{c}\text { Test } \\
\text { statistic }\end{array}$} \\
\hline & $M$ & $S D$ & $M$ & $S D$ & $M$ & $S D$ & \\
\hline Age in years & 61.1 & 8.1 & 60.5 & 8.4 & 60.9 & 8.2 & NS \\
\hline \multicolumn{8}{|l|}{ Health status } \\
\hline vitality & 67.5 & 16.5 & 64.3 & 17.7 & 67.0 & 16.7 & $F=7.0^{*}$ \\
\hline pain & 83.2 & 19.8 & 77.9 & 20.1 & 82.4 & 19.9 & $F=14.8^{*}$ \\
\hline mental health & 75.6 & 15.2 & 73.6 & 15.8 & 75.3 & 15.3 & NS \\
\hline $\begin{array}{l}\text { general feeling of } \\
\text { health }\end{array}$ & 68.2 & 17.2 & 65.2 & 18.2 & 67.8 & 17.4 & $F=5.9^{*}$ \\
\hline $\begin{array}{l}\text { change in health } \\
\text { status }\end{array}$ & 55.4 & 20.2 & 53.4 & 21.2 & 55.1 & 20.4 & NS \\
\hline
\end{tabular}

Note. NS = not significant.

$* p<.01$.

\section{Differences Between Dropouts and Adherers in Terms of Lapses}

Seventy-six percent of the dropouts reported lapses during the study period, compared with $58 \%$ of the adherers $\left(\chi^{2}=53, d f=1, p<.01\right)$. The dropouts also had significantly more and longer lapses than did the adherers (Table 2).

\section{Moment of Dropout}

There were large exercise-program-specific differences in the moment that participants dropped out. People who participated in athletics or cycling dropped out relatively soon (mainly within 8 weeks) after the start of the program, whereas people who skated, played table tennis, or walked mainly dropped out later (Weeks 17-26; Figure 3).

\section{Switching to Another Form of Exercise Program}

Thirty-one percent of the people who dropped out switched to another form of exercise. There were large differences between the exercise programs in switching behavior. For example, many people who dropped out of skating switched to another form of exercise, whereas few people who dropped out of cycling switched to another type of exercise (Figure 4 and Table 3). Many of the people who dropped out switched to fitness, swimming, tennis, or walking. 
Table 1B Background Characteristics of Participants at Baseline

\begin{tabular}{|c|c|c|c|c|c|c|c|c|}
\hline \multirow[b]{2}{*}{ Background variable } & \multicolumn{2}{|c|}{$\begin{array}{l}\text { Adherers } \\
(n=1,475)\end{array}$} & \multicolumn{2}{|c|}{$\begin{array}{l}\text { Dropouts } \\
(n=250)\end{array}$} & \multicolumn{2}{|c|}{$\begin{array}{c}\text { Total } \\
(N=1,725)\end{array}$} & \multirow[b]{2}{*}{$\chi^{2}$} & \multirow[b]{2}{*}{$d$} \\
\hline & $\%$ & $n$ & $\%$ & $n$ & $\%$ & $n$ & & \\
\hline \multicolumn{7}{|l|}{ Sex } & NS & \\
\hline male & 49 & 723 & 45 & 113 & 48 & 836 & & \\
\hline female & 51 & 752 & 55 & 137 & 52 & 889 & & \\
\hline \multicolumn{7}{|l|}{$\begin{array}{l}\text { Marital status } \\
\text { married or living }\end{array}$} & $13.1 *$ & 3 \\
\hline together & 78 & 1,151 & 78 & 195 & 78 & 1,346 & & \\
\hline divorced & 5 & 74 & 7 & 18 & 5 & 92 & & \\
\hline widowed & 14 & 206 & 9 & 22 & 13 & 228 & & \\
\hline $\begin{array}{l}\text { never married or } \\
\text { cohabitated }\end{array}$ & 3 & 44 & 6 & 15 & 3 & 59 & & \\
\hline \multicolumn{7}{|l|}{ Level of education } & $10.8 *$ & 2 \\
\hline high & 18 & 265 & 24 & 60 & 19 & 325 & & \\
\hline middle & 41 & 605 & 49 & 123 & 42 & 728 & & \\
\hline low & 41 & 605 & 27 & 67 & 39 & 672 & & \\
\hline \multicolumn{7}{|l|}{ Housing situation } & NS & \\
\hline house/flat with stores & 70 & 1,032 & 73 & 183 & 70 & 1,215 & & \\
\hline house/apartment & 26 & 384 & 26 & 65 & 26 & 449 & & \\
\hline service flat & 3 & 44 & 0.5 & 1 & 3 & 45 & & \\
\hline elderly home & 1 & 15 & 0.5 & 1 & 1 & 16 & & \\
\hline \multicolumn{7}{|l|}{ Work status } & NS & \\
\hline income from work & 38 & 538 & 41 & 100 & 38 & 638 & & \\
\hline sources & 62 & 892 & 59 & 144 & 62 & 1,036 & & \\
\hline \multicolumn{9}{|l|}{ Physical activity: } \\
\hline \multicolumn{9}{|l|}{ Smoking } \\
\hline \multicolumn{7}{|l|}{ Alcohol consumption } & NS & \\
\hline none & 27 & 398 & 27 & 67 & 27 & 465 & & \\
\hline 1-5 glasses/week & 39 & 575 & 38 & 95 & 39 & 670 & & \\
\hline 6-10 glasses/week & 22 & 325 & 20 & 50 & 22 & 375 & & \\
\hline 11-21 glasses/week & 10 & 147 & 12 & 30 & 10 & 177 & & \\
\hline$>21$ glasses/week & 2 & 30 & 3 & 8 & 2 & 38 & & \\
\hline \multicolumn{7}{|l|}{ Body-mass index } & $12.9 *$ & 3 \\
\hline$<20$ & 3 & 44 & 6 & 15 & 3 & 59 & & \\
\hline $20-25$ & 43 & 634 & 36 & 90 & 42 & 724 & & \\
\hline $25-30$ & 43 & 634 & 48 & 120 & 44 & 754 & & \\
\hline$>30$ & 11 & 162 & 10 & 25 & 11 & 187 & & \\
\hline
\end{tabular}

Note. NS = not significant.

${ }^{a}$ Moderate activity for minimally $30 \mathrm{~min}$ at least 5 days a week.

$* p<.01$. 
Table 2 The Percentage of Participants Who Lapsed in Program Participation in the Last 6 Months, Lapse Frequency, and Length of Lapses

\begin{tabular}{llll}
\hline Variables & $\begin{array}{c}\text { Adherers, } \\
\%(\boldsymbol{n})\end{array}$ & $\begin{array}{c}\text { Dropouts, } \\
\%(\boldsymbol{n})\end{array}$ & $\boldsymbol{\chi}^{2}(\boldsymbol{d} \boldsymbol{f})$ \\
\hline $\begin{array}{l}\text { Occurrence of lapses during } \\
\text { past } 6 \text { months }\end{array}$ & & & $28.6(1)^{*}$ \\
$\quad$ yes & $58(856)$ & $76(190)$ & \\
$\quad$ no & $42(619)$ & $24(60)$ & $63.6(4)^{*}$ \\
$\begin{array}{l}\text { Frequency of lapses } \\
\text { >once per month }\end{array}$ & $28(240)$ & $58(110)$ & \\
$\quad$ once per month & $20(171)$ & $11(21)$ & \\
$\quad$ once per 2 months & $18(154)$ & $9(17)$ & \\
$\quad$ once per 3 months & $15(128)$ & $9(17)$ & \\
$\quad<$ once per 3 months & $19(163)$ & $13(25)$ & \\
Length of lapses & & & \\
$\quad$ 1 week & $33(283)$ & $18(34)$ & \\
2-3 weeks & $40(342)$ & $19(36)$ & \\
4-6 weeks & $16(137)$ & $16(31)$ & \\
$>6$ weeks & $11(94)$ & $47(89)$ & \\
\hline
\end{tabular}

$* p<.01$.

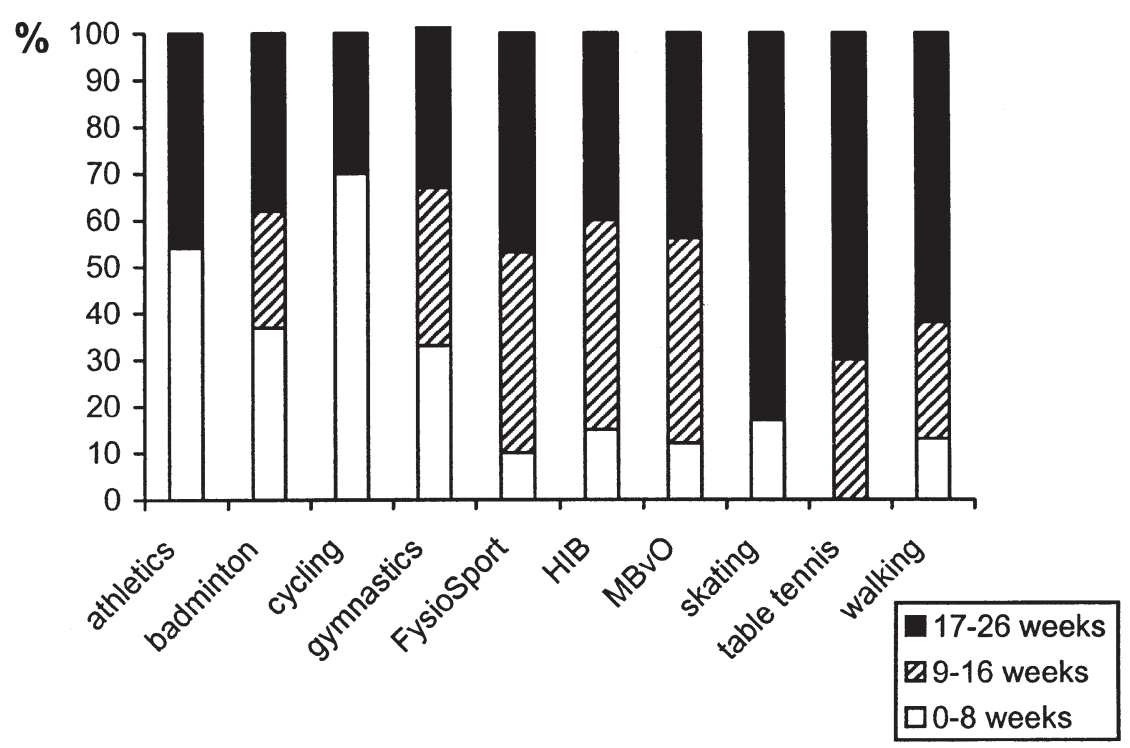

Figure 3 - Moment of dropout (comparison months 0-8 weeks vs. 9-16 weeks and 17-26 weeks; 0-100\%). 


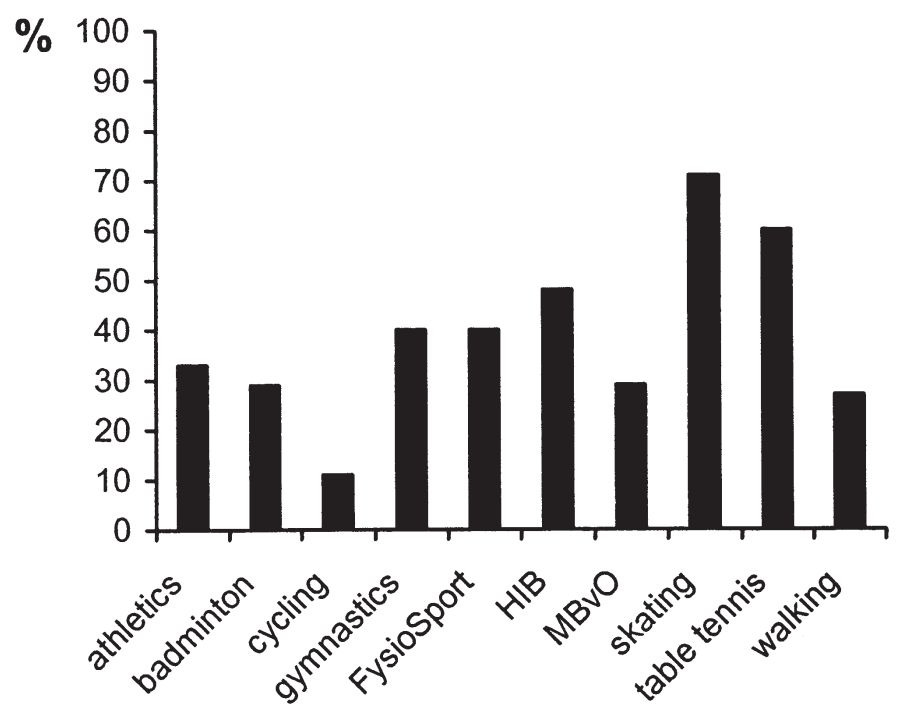

Figure 4 - The percentage of people who dropped out $(n=250)$ who switched to another form of exercise.

\section{Discussion}

This study investigated the incidence and timing of dropout among seniors taking part in organized exercise programs in the Netherlands. The average dropout incidence was 0.15 per 6 months.

In the general population, the average dropout incidence in exercise programs is about 0.50 during the first 6 months (Carmody et al., 1980; Dishman, 1982; Dishman \& Sallis, 1994; Oldridge, 1988). This difference in dropout incidence might partly be because we focused on organized exercise programs. Older adults often adhere better to a specific kind of exercise behavior, whereas younger people tend to change more often. This might be because of a stronger sense of responsibility, especially when social interaction is involved, such as in a group-based exercise program. Older people might also have more time for exercise programs than younger people do.

The overall dropout incidence among seniors attending organized exercise programs in the Netherlands was lower than that reported in U.S. and Canadian studies. Ecclestone et al. (1998) found that in organized exercise programs for seniors in Canada, the dropout incidence was 0.41 during the first 6 months. In that study the exercise programs consisted mainly of aerobics and fitness classes, whereas we compared 10 different types of exercise programs. It should be noted that we observed considerable variations in the dropout incidence for the different programs, with FysioSport having the highest dropout rate. FysioSport is an aerobics and fitness class and therefore the form of exercise most similar to the 


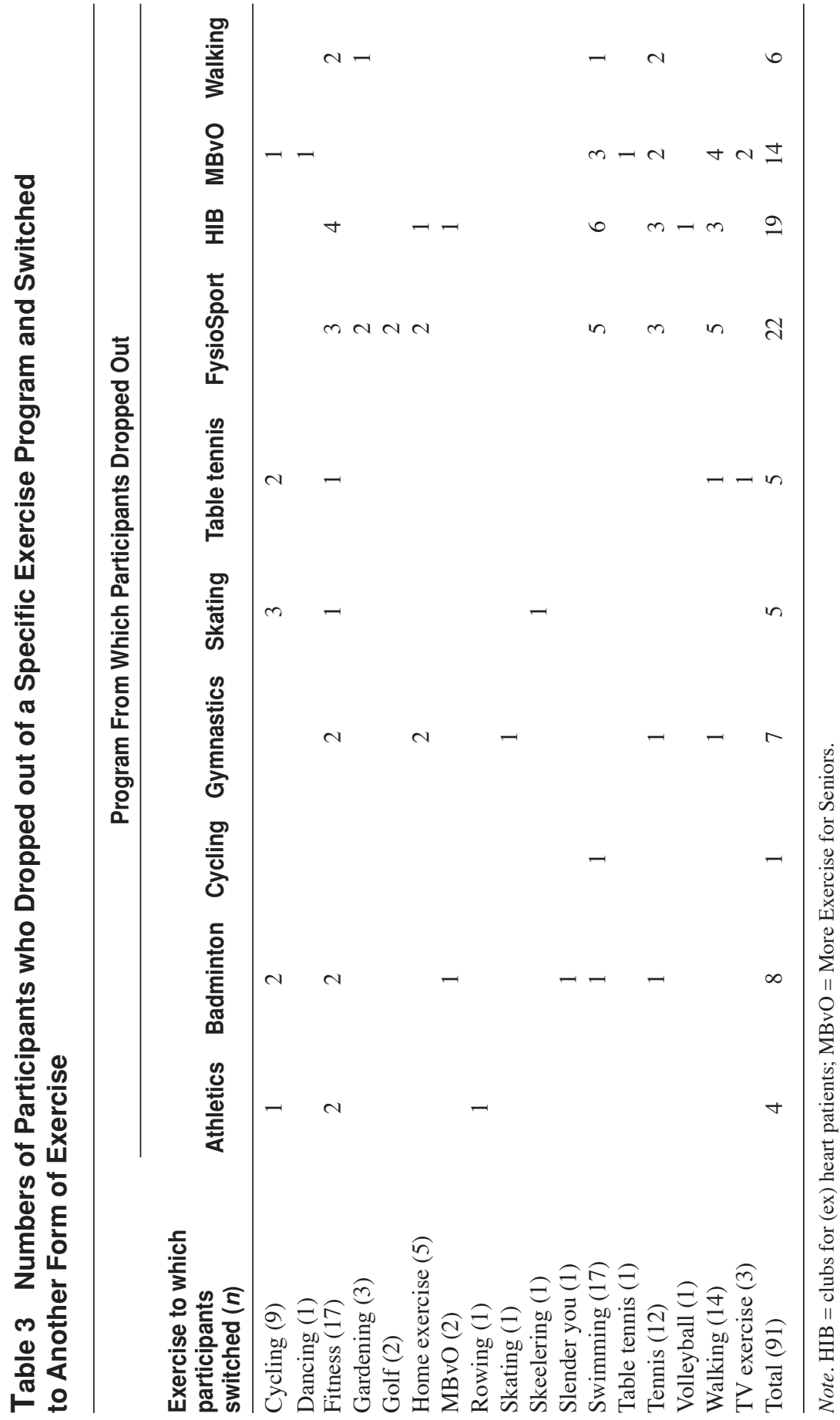


exercise programs of Ecclestone et al. The dropout incidence for FysioSport was comparable to that reported by Ecclestone et al. (0.37). People who dropped out were asked whether they did so because of the intensity of the program. This reason was, however, not mentioned in FysioSport. This high dropout incidence might in part be because of the cost, because FysioSport is a relatively expensive exercise program.

The dropout incidence appeared to vary according to marital status, level of education, housing situation, and BMI. Among those who dropped out, there were significantly fewer with a lower level of education. These results are in accordance with those of King et al. (1997), but on the whole there is little information in the literature about the association between level of education and dropout. Among the dropouts there were significantly more people who had always been single and significantly fewer widowed people. This might be because organized exercise programs are an important aspect of the social life of people who have lost their partners, because they offer the chance to make new social contacts. Among the dropouts were significantly more overweight and underweight people. In the focusgroup interviews TNO held with seniors $(50+)$ before the study, being overweight was mentioned as an important determinant of dropout, although there is little scientific evidence to support this. The results indicate that this aspect warrants further investigation, especially because exercise is often recommended to overweight people. The higher dropout incidence among people with a BMI under 20 was unexpected and difficult to explain. Low weight might be associated with underlying illnesses or frailty, but because of the relatively low number of participants in this subgroup this hypothesis cannot be proven. There were significant differences in vitality, pain score, and general feelings of health between the dropouts and the adherers. People with a lower perceived health status tended to drop out more often than those with a higher perceived health status. Other investigators have reported poor health to be a determinant of dropout (Dishman \& Sallis, 1994, Ecclestone et al., 1998; Martin \& Sinden, 2001; Rhodes, Martin, \& Taunton, 1999). This is in accordance with the results of the current study.

The literature suggests that dropout mainly occurs during the first 3 months of a program (Carmody et al., 1980; Dishman, 1982; Dishman \& Sallis, 1994; Oldridge, 1988). We found that the type of exercise program influenced the moment that people dropped out. In several programs (i.e., skating, table tennis, and walking) participants tended to drop out after 4 months, whereas in other programs (i.e., cycling and athletics) people mainly dropped out in the first 8 weeks. It seems that certain exercise programs are more prone to early dropout than others.

This study is one of the first to investigate whether seniors who drop out of an exercise program actually switch to another form of exercise. Thirty-one percent of the people who dropped out subsequently took up another form of exercise. There were large differences in such switching behavior among the 10 exercise programs. For example, many people who dropped out from skating took up another form of exercise. This might be influenced by the seasonal aspects of the sport, because people can only skate in the winter and thus tend to take up another sport in the summer. Three of the 5 skaters who took up another form of exercise took up cycling. Few of the people who dropped out of cycling took up another type of exercise. Ecclestone et al. (1998) found that in a period of 3 years $21 \%$ of the participants switched to another exercise program in their center. They did not, however, take 
into account the participants who quit an exercise program and switched to another form of exercise outside of their initial center. We took other forms of exercise into account, which might explain the differences in results (21\% in Ecclestone et al. in 3 years vs. $31 \%$ in this study in 6 months). It was found that people who switched from one program to another often switched to fitness, swimming, tennis, or walking, forms of exercise that appear to be popular among seniors (Ooijendijk et al., 2002). It was not reported, however, that people switched to another sport because they preferred it or thought it to be more beneficial to their health.

This study had a number of limitations. The number of dropouts might have been biased by nonresponse (Figure 1). A random nonresponse analysis revealed that participants had not responded because they were ill or injured $(20 \%)$, had moved to another city (12\%), or had died (4\%). Based on these responses one would certainly expect these people to have dropped out of the exercise programs. The dropout incidence would then be about 0.20 . Although different types of exercise were included, it was not possible to ensure that the same number of participants followed each type of exercise program, which might have biased the results. In this study the occurrence, amount, and duration of lapses were taken into consideration. An aspect that could have offered additional information was the time point of the lapse(s), but this information was not recorded. In future studies it could be added, if the risk of memory bias is low.

In conclusion, the results suggest that the dropout incidence for organized exercise programs for seniors $(0.15)$ is lower than that for such programs for the general population. There are substantial program-specific differences in dropout in seniors. Of the people who dropped out of an exercise program, $31 \%$ took up another form of exercise. Future studies should take switching behavior into account when dealing with dropout from exercise programs.

\section{Acknowledgments}

The authors would like to thank the Netherlands Health Research and Development Council (ZonMw) for financial support (Grant Number 2200.0024). We would also like to thank the guidance board, the intermediaries, and, last but not least, all the participants in the study.

\section{References}

American College of Sports Medicine. (1998). American College of Sports Medicine position stand. Exercise and physical activity for older adults. Medicine and Science in Sports and Exercise, 30, 992-1008.

Carmody, T.P., Senner, J.W., Malinow, M.R., \& Matarazzo, J.D. (1980). Physical exercise rehabilitation: Long-term dropout rate in cardiac patients. Journal of Behavioral Medicine, 3, 163-168.

Dishman, R.K. (1982). Compliance/adherence in health-related exercise. Health Psychology, 1, 237-267.

Dishman, R.K., \& Sallis, J.F. (1994). Determinants and interventions for physical activity and exercise: Physical activity, fitness and health. International proceedings and consensus statement. Champaign, IL: Human Kinetics. 
Ecclestone, N.A., Myers, A.H., \& Paterson, D.H. (1998). Tracking older participants of twelve activity classes over a three year period. Journal of Aging and Physical Activity, 6, 70-82.

Kemper, H.C.G., Ooijendijk, W.T.M., \& Stiggelbout, M. (2000). Nederlandse Gezonde Beweeg Norm. Tijdschrift voor Sociale Gezondheidszorg, 78, 180-183.

King, A.C., Blair, S.N., Bild, D.E., \& Dishman, R.K. (1992). Determinants of physical activity and interventions in adults. Medicine and Science in Sports and Exercise, 24, S221-S236.

King, A.C., Kiernan, M., Oman, R.F., Kraemer, H.C., Hull, M., \& Ahn, D. (1997). Can we identify who will adhere to long-term physical activity? Signal detection methodology as a potential aid to clinical decision making. Health Psychology, 16, 380-389.

Lee, J.Y., Jensen, B.E., Oberman, A., Fletcher, G.F., Fletcher, B.J., \& Raczynski, J.M. (1996). Adherence in the training levels comparison trial. Medicine and Science in Sports and Exercise, 28, 47-52.

Martin, K.A., \& Sinden, A.R. (2001). Who will stay active and who will not? A review of older adults' adherence to randomized controlled trials of exercise. Journal of Aging and Physical Activity, 9, 91-114.

Oldridge, N.B. (1982). Compliance and exercise in primary and secondary prevention of coronary heart disease: A review. Preventive Medicine, 11, 56-70.

Oldridge, N.B. (1988). Cardiac rehabilitation exercise programme. Compliance and compliance-enhancing strategies. Sports Medicine, 6, 42-55.

Ooijendijk, W.T.M., Hildebrandt, V.H., \& Stiggelbout, M. (2002). Lichamelijke activiteit in Nederland in 2000. In W.T.M. Ooijendijk, V.H. Hildebrandt, \& M. Stiggelbout (Eds.), Trendrapport bewe gen en gezondheid 2000-2001. Hoofddorp/Leiden, The Netherlands: TNO Arbeid/TNO Preventie en Gezondheid.

Pate, R.R., Pratt, M., Blair, S.N., Haskell, W.L., Macera, C.A., Bouchard, C., et al. (1995). Physical activity and public health. A recommendation from the Centers for Disease Control and Prevention and the American College of Sports Medicine. Journal of the American Medical Association, 273, 402-407.

Rhodes, R.E., Martin, A.D., \& Taunton, J.E. (1999). Factors associated with exercise adherence among older adults. Sports Medicine, 6, 411.

SPSS Inc. (2003). Statistical package for the social sciences (release 11.5). Chicago: SPSS.

U.S. Department of Health and Human Services. (1996). Physical activity and health: A report of the Surgeon General. Atlanta, GA: U.S. Department of Health and Human Services.

van der Zee, K.I., \& Sanderman, R. (1993). Het meten van de algemene gezondheidstoestand met de RAND-36: een handleiding. Groningen, The Netherlands: Noordelijk Centrum voor Gezondheidsvraagstukken.

Ware, J.E.J., \& Sherbourne, C.D. (1992). The MOS 36-item short-form health survey (SF36). Medical Care, 30, 473-483. 